\title{
Shopping as a 'networked experience': an emerging framework in the retail industry
}

\begin{abstract}
Purpose. The paper aims to devise a comprehensive framework of the emergent shopping experience as the result of the combination of store access and the use of communication technologies, particularly social media.
\end{abstract}

Design/methodology/approach. The paper builds on a set of 20 semi-structured interviews to London-based young consumers aged 18-23 and adopts an exploratory approach aimed at understanding the broad relationship between retailing and social media use.

Findings. Our findings highlight how an intensive use of social media and digital communication technologies emerges as an integral part of the shopping experience inside and outside the store.

Research limitations/implications. Drawing upon the notion of the "experience economy", scholars and practitioners are actually pushed to reconsider the role of traditional shopping as instore experience that is evolving fast as an effect of the continuous progress into communication technologies. This concept contributes to knowledge development by linking research in retail with work in the area of consumer culture.

Practical implications. Marketers and retailers should consider that the shopping experience is no longer limited to the physical point of sale. This means that retailers should be able to provide a shopping experience that is natively networked.

Originality/value. We identify the emerging "networked experience" of shopping, which derives from the consumers' widespread usage of new communication technologies to collect information, their willingness to share part of this information with others, while creating new digitally-mediated relationships with retailers. 
Keywords: Retailing; shopping experience; service economy; experience economy; networked experience; consumer co-creation

Paper type: research paper

\section{Introduction}

The shift towards a service economy (Vargo and Lush, 2004, 2008; Gallouj et al., 2015) has pushed organizations to move from a normative view that focuses on consumer engagement in value cocreation, to consider how value co-creation takes place in a system of service exchange (Akaka et al., 2015). For this reason, retailers seemingly face a redefinition of their role as integrators of services rather than distributors in the emerging value network in retail settings (Lush et al., 2007; Hagberg et al., 2016). Simultaneously, the increasing demand for knowledge-intensive service innovations and the continuous search for interactive and creative solutions in service production (Burke, 2002; Lusch and Spohrer, 2012; Kindstrom et al., 2013) is rapidly changing the retail industry (Demirkan and Spohrer, 2014; Hristov and Reynolds, 2015; Hagberg et al., 2016; Pantano, 2016; Bertacchini et., 2017; Pantano et al., 2018; Willems et al., 2017). Indeed, the search of innovative solutions results in a novel concept of retailing that overcomes the traditional physical boundaries of the store (i.e. physical stores size, opening hours) (Pantano and Gandini, 2017) to foster the growth of new forms of commerce strongly based on the usage of technologies such as online and mobile for shopping. Among these forms, the "social commerce" emerging from the integration of social media and internet shopping is largely acquiring the interest of scholars and practitioners (Lin et al., 2017; Wang and Yu, 2017). Moreover, the new forms of shopping, with emphasis on the social commerce, lead to different forms of sociality among consumers as consequence of the increasing role of technology, especially among younger consumers who are instensive users of smartphones and social media technology (Pantano and Gandini, 2017). The 
success of this emerging scenario strictly rely on the integration and coordination of the actors' effort (i.e. retailers, sellers, employees, consumers) to achieve the same goal of having the highest value of the final service, which all actors equally contribute to create (co-creation) (Letaifa et al., 2016). Indeed, the integration of technologies in selling activities generates positive effects in retail settings in terms of (successful) adaptive engagement behavior based on the information collected through the technology (Rapp et al., 2015).

In the new retail settings based on intensive and extensive usage of social media and internet solutions, e-WOM (electronic word of mouth communication) and user-generated contents such as consumers' online posts and reviews becomes the key drivers for consumers' buying decision (Lin et al., 2017; Wang and Yu, 2017), and represent a kind of social support mediated by the quality of the relationships between the users-consumers and social networking web site (Liang et al., 2011; Zhang et al., 2014). These social interactions might further emerge from the observation of other consumers' purchases as driver of purchase decision (Wang and $\mathrm{Yu}, 2017$ ). This has led research to consider social commerce as a shift in consumer behavior from individual-based purchase decisions to collaborative and social shopping (Chen and Shen, 2015). For these reasons, Yadav and colleagues (2013) define the concept of social commerce as referring to all "exchange-related activities that occur in, or are influenced by, an individual's social network in computer-mediated social environments, where the activities correspond to the need recognition, pre-purchase, purchase, and post-purchase stages of a focal exchange" (p. 312). Thus, it consists of an evolution of e-commerce involving social technologies, community interactions and commercial activities (Huang and Benyoucef, 2013; Liang and Turban, 2011; Yadav et al., 2013; Hajli and Sims, 2015; Lin et al., 2017; Lu et al., 2016; Zhang and Benyoucef, 2016).

Drawing upon the potential of social commerce, some authors are starting to consider the mobile context (namely mobile social commerce) and to question the role of mobile technologies in consumers' daily life as the result of the widespread use of social networking apps through mobile devices by customers in brick and mortar stores (Hew et al., 2016; Pantano and Gandini, 2017). 
Indeed, the retail industry has embraced the idea of making the store more accessible to consumers digitally, for instance through the development of smart shopping channels to enhance the perceived sense of wellbeing and social inclusion (Papagiannidis et al., 2017).

Yet, to our knowledge no existing research has addressed the shopping experience beyond its meaning of an experience related to a place for shopping (i.e. a "store experience"), rather as an experience that revolves around the combination of store access and the usage of communication technologies, particularly social media, in a comprehensive framework.

The aim of this paper is therefore to examine the nature of the shopping experience in the new retail environments and assess its relationship with new communication technologies (i.e. social media). In doing so, we will look specifically into the cultures of 'networked shopping' that characterise younger consumers who are intensive users of smartphones and social media technology, to highlight the extent to which this experience shifts from being a store-based experience to a "networked experience", and discuss the implications of this evolution.

The paper is organized as follows: the subsequent section will discuss the shopping experience in terms of social and store experience. Section 3 will introduce the key aspects of experience economy, while section 4 will present the methodology of the research. Sections 5 and 6 will discuss the key findings and their implications for both scholars and practitioners respectively.

\section{Shopping as store experience}

In the retail literature, an important body of research focuses on creating a superior retail experience by providing an entertaining and novel in-store experience to engage more consumers (Backstrom and Johansson, 2006; Verhoef et al., 2009; Hagberg et al., 2016; Pantano, 2016, Willems et al., 2017), this means that shopping activity is usually limited to the in-store experience. When pleasant, it leads to emotional and behavioral responses (i.e. unplanned spending and time 
effectively spent in the store, more purchases, etc.) (Donovan et al., 1994; Baker et al., 2002; Yoon, 2013).

Extending the service-dominant logic (Vargo and Lusch, 2004), it has been argued that the store experience is co-created within the stores by consumers' interactions with store elements, such as the atmosphere and store design (including colors, music, lights, etc.) (Yoon, 2013; Campo and Breugelmans, 2015) and by the social interaction consumers engage in within the store, including the relationships developed with the store personnel and other consumers (Verhoef et al., 2009; Mohan et al., 2012; Pantano and Migliarese, 2014; Rapp et al., 2015), which might have higher or lower importance according to the product category (Burke, 2002). Therefore, the store experience consists of the place (context) where the experience takes places along with the service provided and (eventually) co-produced. Some authors also hypothesized that the store experience starts even outside the store, in front of the store windows which are capable to influence consumer entry decision (Pantano, 2016) as the first touchpoint with the retail settings.

Consumers demand of memorable shopping experience increases (Klein et al., 2016) and pushes retailers to develop new practices to satisfy this demand, i.e. by creating pop-up temporary stores (Klein et al., 2016) or flagship/concept stores (Jones et al., 2010), and introducing innovative and interactive technologies (Demirkan and Spohrer, 2014; Bertacchini et al., 2017; Hagberg et al., 2016; Pantano, 2016; Willems et al., 2017), etc.

Nonetheless, shopping is also an eminently social experience (Pantano and Gandini, 2017; Lu et al., 2016). For instance, consumers usually spend more time and purchase more goods when shopping with others (e.g. friends and relatives) (Kim et al., 2013). Furthermore, purchase decisions are often influenced by consumers' social interactions with others (either consumers or vendors) for what concerns being advised on almost unknown products (Pantano and Gandini, 2017) and in their relationship with notions of status and identity (Reinstaller and Santiov, 2005). These social influences occur through word of mouth communication (WOM) (Lee et al., 2011; Mishra et al., in press.), observational learning (Chen et al., 2011; Lu et al., 2016), and social support (Zhang et al., 
2014; Mohan et al., 2012; Pantano and Migliarese, 2014). In particular, word of mouth is considered a form of information seeking that occurs when consumers suggest or demand the opinion of others before choosing. Social support refers to "an individual's experiences of being cared for, being responded to, and being helped by people in that individual's social group" (Liang et al., 2011, p. 71). This information adds new knowledge to consumers' beliefs of products and services, increases/decreases the credibility of a company, and creates awareness and interest towards a certain product or brand (Mishra et al., in press.; Zhang et al., 2014). Similarly, the observation of other consumers' behavior influences the purchase decision in both online and offline retail settings (Zhang, 2010; Wang and $\mathrm{Yu}$, 2017). Interacting with store personnel contributes also to create a pleasant store experience when personnel is perceived to have the capacity of providing a good service and supporting consumers while shopping with advice and suggestions when requested (Mohan et al., 2012; Pantano and Migliarese, 2014; Rapp et al., 2015), with positive consequences for consumer purchase behavior. For these reasons, social support is largely acquiring the attention of scholars particularly with regards to the role of social media and online social environments, with digitally-mediated forms of interaction among groups of consumers emerging as key drivers of purchase behavior (AmLiang et al., 2011). However, social interactions related to the store experience are no longer limited to socialising in the store, nor it requires the physical presence of other consumers (including friends, partners, relatives, etc.) or sellers. In fact, social networks such as Facebook and Twitter provide consumers with access to a larger pool of social connections able to interfere with the shopping experience at various levels. Thus, consumers increasingly consider stores and shopping malls as places where to satisfy some broader experiential needs (Nsairi, 2012). A preliminary study of Rapp and colleagues (2015) showed how the increasing usage of technology impacts employees selling activites and the relationships built and maintained with consumers. Thus, this study represents the starting point of understanding the possible changes in shopping as social experience when technology plays a dominant role. In this direction, the subsequent study by Pantano and Gandini (2017) shows that 
young consumers consider shopping as an individualized practice in the store, while preferring building and maintaining their social interactions while shopping through social media. This causes the appearance of forms of "network sociality" (Wittel, 2001) within the store, which is increasingly characterized as an environment where digitally-mediated social interactions coexist with physical ones as consumers can exchange digital messages, or chat, with others. This combines with outstore practices, such as the access to online social environments or community support groups, the posting of purchases or reviews on social media, and their influence for the formation of an opinion on consumers, as well as in terms of value creation, which is often significant (Arvidsson and Caliandro, 2016).

This leads us to question the nature of the shopping experience as an entire element in this changing context, and the extent to which the dimension of digitally mediated social interactions affects the behaviour of consumers in a retail context. To address this aspect, it seems useful to drawing upon the idea of the "experience economy" (Pine and Gilmore 1998), which has been influential over the past decades in the area of consumer culture theory (CCT) and fostered the subsequent discussion around co-creation and value, particularly around brands (Arvidsson 2005, 2013). In the next section, we will look back at the notion of "experience economy" and assess its relevance in the present context in pair with discussing the role of identity and the self in consumption (Belk, 1989; Ahuvia, 2005) in the rise of social media (Belk, 2013).

\section{The experience economy, consumption and the "extended self"}

From a sociological point of view, consumption is conceived as the social, cultural and economic process of choosing a product or good (Zukin and Maguire, 2004). The idea of "experience" in this sense keeps together the notions of cultural capital, economic capital and social status and grasping the various facets of individual behavior and decision-making when it comes to choose a product or good to buy (Caru and Cova, 2003). The essay on the "experience economy" by Pine and Gilmore 
(1998) was pivotal in this sense, while it tied the notion of experience to that of economic value in the argument that experiences are a distinct consumer need that can, and should, be nurtured accordingly. They argue that an experience "occurs when a company intentionally uses services as the stage, and goods as props, to engage individual customers in a way that creates a memorable event. Commodities are fungible, goods tangible, services intangible, and experiences "memorable"" (1998: np). This work resulted to be instrumental in highlighting how consumption was undertaking a process of "fusion of entertainment and commerce" (Arvidsson, 2005, p. 246) and effectively offered the baseline for the development of critical research on brands that became prominent in consumer culture theory in the following decade (Lury, 2004; Arvidsson, 2005, 2009). In particular, Arvidsson $(2005,2009)$ has argued that brands play an instrumental role not only to foster the desire and social aspiration that drives consumption choices, but also to create value for postindustrial informational capitalism, since they represent the element through which customer activity gets appropriated by corporations and transformed into co-creation of value for profit generating activities.

Alongside the idea of the "experience economy", the notion of the "extended self" (Belk, 1989) emerged as a heuristic device able to encapsulate how consumer behaviour is also inextricably linked to the individual notions of possession that consumers attach to their purchases. This notion has been influential in the area of consumer culture research (Ahuvia, 2005; Atwal and Williams, 2009) and its application has been recently extended also to the growth of social network sites (Belk, 2013) in the attempt to revisit the original theory and update it to the new framework. This attempt principles on the idea that the conception of the "self" in social network sites is particularly central to the experience of users, and therefore consumer goods offer a particularly apt instrument for the display of individual's preferred image online. It is particularly evident in the case of luxury brands, which determine the emergence of "brand publics" able replace brand communities (Arvidsson and Caliandro, 2016) and for users themselves who sometimes go in search of a "microcelebrity" (Marwick, 2015). 
However, the research around retail has been substantially oblivious to this discussion. Yet, there seems to be an emergent relationship between social media and retail insofar as social media become not only an important part of the social dimension of shopping (Pantano and Gandini, 2017), but also as a very powerful tool to enhance the shopping experience as such. In an attempt to adapt Belk's original notion of the extended self to the digital arena, Sheth and Solomon (2014) include shopping as one of the key changes in the "extension" of the self throughout the advancement of digitally-mediated forms of communication. Their description entails product selections "made in consultation with a "shadow cabinet of trusted advisors" (Sheth and Solomon, 2014, p. 128), up to online postings that document recent purchases and the rise of "social shopping sites" which provide group feedback on items. Our paper aims at providing the missing link between social media, retail settings and the social dimension of shopping experience, while synthetizing current research on retail with established and current research on the shopping experience, the self and digital media in consumer culture theory in a comprehensive framework.

\section{Methodology}

The paper builds on a set of 20 semi-structured interviews to London-based young consumers aged 18-23, and adopts an exploratory approach aimed at understanding the broad relationship between retailing and social media use for shopping purposes. The sample is made of a balanced group of interviewees (10 males, 10 females); the large majority of them come from the UK or the EU, and study for an undergraduate degree in disciplines such as advertising, marketing or journalism. In line with the study by Oberseder et al. (2011), we apply here a qualitative research framework that is aimed at investigating practices, perceptions, opinions and beliefs about the issue here discussed. Yet, in contrast with their approach, we purposefully chose to focus more closely on the specific segment of consumers who seem to be at the centre of this evolution: younger consumers, who are both accustomed to shopping as a regular activity and regular social media users. While this does 
not enable us to engage in generalizations or comparisons with older cohorts of consumers, considering the scarce diversity in the sample, the choice of interviewing a sample of consumers that is made of young and social media savvy participants with a generally high interest in shopping is aimed at investigating closely the retail cultures and practices of a specific set of consumers, who are deemed to be more prone to discuss the encounter between their shopping experience and their social media habits. This therefore allowed us to develop a deep set of insights on this specific group, and explore in greater depth the 'networked' cultures of shopping of precisely those consumers who are at the forefront of this evolution.

The choice of interviewing university students for this research also requires a brief explanation. The sample here constructed should be seen as a 'convenience sample', being in other words the most convenient sample for researchers to access, that is relevant to the research question under investigation as illustrated earlier. This is a common strategy in social research (see Robinson, 2014); also, the use of students as 'convenience sample has a long history in consumer research, having found useful application especially in studies that adopt an exploratory rationale (see Ferber, 1977). Interviews were conducted at two London universities, lasted on average 45 minutes each and were tape recorded for purposes of transcription. All interviewee information has been anonymised and participants were granted the possibility to opt out of the research at any stage. Interview data analysis was conducted by blending the principles of "thematic" and "narrative" analysis (Bryman, 2015), and mainly consisted in the search for recurring themes and the analysis of the way participants described perceptions and experiences in their lives as consumers. This practice has obvious drawbacks, as it does not entail any systematic coding of responses nor it consists in the application of a structured methodology, but we believe it is a highly effective way to grasp the multi-faceted aspects that link together the notions of "shopping experience" and social media use in a retail context by users/consumers, and to offer insights that may be useful for further research in this area. 
5. Key findings As the sample is purposely made of participants who are accustomed to both shopping and social media use, we expected a highly-intensive use of these technologies. This is clearly reflected in the findings; all but one interviewees declare a daily use of social media apps, and a large majority of them declare the use of social network sites in a retail context for a variety of purposes, that include checking prices and availability, comparing an item with similar others, up to the involvement of advisors who are not present in the same environment. Based on the thematic and narrative analysis of interviews, three main qualitative dimensions of the digitally-mediated shopping experience have been highlighted, and will be explored in the next sub-sections. These

are: i) The role of online shopping activity as a support to the store experience; ii) The instrumental use of social media to the aim of empowering the shopping experience; and iii) The role of social media as 'aspirational devices' and their capacity to influence the purchase decision.

\subsection{Online shopping activity as a support to the store experience}

The role of online shopping emerges from our research as an aspect of the shopping experience in a seamless blend with the visit to a real point of sale. The role that platforms such as Amazon, eBay or Alibaba play in this scenario is not necessarily that of a cheap alternative to visiting a store, rather a 'virtual window shopping' that in many cases is likely to foster or ignite the actual visit to a physical store. As Mick (pseudonym), an average consumer who does not see himself belonging to any particular style, goes shopping 'occasionally' but is very much into Facebook and Twitter, explains:

"I use Amazon and eBay, mostly... I think online I buy much more, 'cos for me it's more convenient and easy to just press a button and say "buy now", and I kinda like going to the shop and look around, that's like the best thing but online now you can do the same thing, compare different sizes, and stuff, and with something like Amazon Prime you can get it fast anyway...I mean, if it's 
something like clothes I would definitely go out to buy it, cos online it's kinda hard to get sometimes, but if it's a game or series I will use online" (Participant 11, male, British, 22)

This practice is quite diffused among our participants. Online shopping activity emerges in our findings as an aid to the store experience, with consumers using digital resources for a number of aims. These include price comparison and a cross reference of store availability and alternative options among which to choose. Interestingly, this does not necessarily lead to an online purchase but actually reinforces the experiential side of their shop visit. Adrian (pseudonym) believes his shopping habits are typical of how his generation approaches consumption and the retail experience. In the quote below, he explains how this represents an experiential dynamic that feeds into his broader shopping experience, highlighting how his practices are especially representative of how different these are from those practiced by his parents - precisely because he is a sort of "digital native" to the networked shopping experience:

"I think my parents come from a generation where they thought if you go into a shop you can try everything, you can look at it first hand... I think, me personally I don't see much use in that because, especially with Amazon Prime I can get something the same day, and if I don't like it I can send it back, it really makes no sense to me especially for someone who doesn't drive or anything, is a lot more hassle to go into town [...] Usually if I'm in an area where there's shops, it would be a secondary thing, I wouldn't go primarily for the shop" (Participant 10, male, British, 23).

In practice, this aid role particularly involves the social media ecosystem and the use of social network sites such as Instagram and YouTube, where consumers can find reviews, opinions and suggestions about products. Anna (pseudonym) explains how this works:

"I'd say online shopping definitely helps me when I go into the store, cos I'd already recognise products that I've seen online... so it'd just kind of confirm my willingness to buy a product 
offline... I'd say sometimes I feel very impulsive and I just want to buy on the spot, and this is sort of heightened when I see some kind of blog, or vlog, on YouTube or Instagram hype about the products, that would make me want to buy it even more impulsively, but if that is something that I need more than an actual necessity, like "oh I need jeans", I'll have a look online, stores like Mango or Zara, I'll have a look at what they have to offer then I'll go to the store and see if I like it, then I'll buy it" (Participant 18, female, Norwegian, 23).

This brings us to observe more closely the role social media play more broadly in the shopping experience. As we are about to see, there seems to be a clearly instrumental approach adopted by consumers who use social media somewhat strategically across the whole shopping experience, from prior to after the purchase.

\subsection{The instrumental use of social media use in the shopping experience}

The relationship between digital technologies, particularly social media, and the retail environment is more complex than what current accounts depict. What emerges from our study is the existence of a multi-dimensional pervasiveness of social media throughout the whole shopping experience. Social media add an important layer to the shopping experience - the 'networked' layer here outlined - insofar as it renders the visit to a store the final step in a broader set of actions that locate the shopping activity in a social and cultural ecosystem.

A first aspect to this layered networked experience is anticipation. As seen, prior to the visit to a real point of sale the young consumers we interviewed seem to often indulge in a "virtual window shopping practice" through a variety of digital-based resources. This means that their consumption choices within a store are partly influenced by what found online about an item or good, with emphasis on the opinion of others. See for instance how Magda (pseudonym), a 22-year-old student from Romania, describes this practice of searching for information online before visiting a store: 
"I tend to look at reviews precisely because I may not know about things...so I tend to look what others... a lot of other people have said about it. And I try to compare like the number of really good and really bad reviews, cos you tend to get both in any given case. But I usually try different websites as well... I tend to buy mostly on Amazon but if I'm not satisfied with the reviews I find there I tend to try another website, and look for other information about this. And eventually I ask a friend if I'm still unsure" (Participant 3, female, Romanian, 22).

The quote above illustrates how this is primarily a social experience; in this, the key aspect is that young consumers use these resources to scout for advice and opinions from others. Hari (pseudonym), a British Indian 23-year-old who follows a number of blogs on YouTube, explains how the opinions of others, particularly prominent bloggers, add to her shopping experience:

“[Do you trust bloggers reviews?] Definitely, definitely! For instance, I bought this make up brush...all of YouTube, social media...the only reason I bought was social media, and YouTube and I'm so thankful I did. There was this lady I used to follow, and the stuff she made was really lovely and I definitely bought things because of her, I trusted her work" (Participant 2, female, British, 23).

Interestingly, the topic of make-up recursively occurs among female interviewees as an example of the extended shopping experience driven by the instrumental use of social media for the purchase decision. Similar to Hari, Marie (pseudonym), a French 23-year-old advertising student, tells how online resources come to be part of the shopping experience as an important aspect of the decisionmaking process:

"Make up... is actually a very good example. one of my friends introduced me to all those vlogs, you know on YouTube... and since I'm quite loyal towards bloggers... there's this lady called Judy, 
she does videos on YouTube, she started out with make-up tutorials, and now she just vlogs about her life... and I also follow her FB page and comment on her videos... [...] I was looking for a mascara and she has same kind of lashes I do... A good friend of mine introduced me to her so that's also a topic for conversation...it definitely influenced me" (Participant 17, female, 23, French).

Put differently, as a result of the social dynamics these propel, digital technologies foster processes of peer recognition, identity and status that are at the core of the experiential side of consumption. Discussing, engaging in conversation and seeking advice online is daily practice in the group of consumers here observed as social media users. This, for many, extends to the shopping experience, adding an important element of sociality to preferences and purchase decisions - an element which was previously found elsewhere, and which online social environments tap into more directly. Adrian describes how the formation of a base of opinions for his shopping behavior often revolves around digitally-mediated exchanges with others (in his case, Twitter friends):

“With Twitter, for instance, it's become a lot easier to involve friends in discussions...for instance I would just quote my friends' Twitter handle and they would see it initially, and start a conversation about it...not necessarily in a discussion on "should I buy it", you just ask their opinion if they'd buy it for themselves, and that usually influences my opinion. Again, this is all self-commentary on something I don't like about myself, that I like some other people's opinions when I buy things, but when it comes to some big purchase, it does influence my decision, if my friends say they hate it or it's sad, or if maybe it's like a different subculture than the one I'm going for... what I'm just saying is my friends say "oh, you don't wanna be seen as that kind of person...so you probably want to avoid it, that would influence my decision, whether I buy that product" (Participant 10, male, British, 23). 
Another element of expansion to the shopping experience that digital spaces enable is documentation. It seems clear from our conversations that for our participants the shopping experience does not end with the visit to a store and the purchase that may come with it. Actually, the documentation and sharing of the purchase with others through a social network site has come to represent an integral part of the shopping experience of many of our interviewees, either as 'posters' or 'respondents'. However, as concerns the proactive side of this activity, a number of participants seem to be more reluctant to admit this behavior, perhaps for concerns of social desirability, whilst others are more enthusiastically recounting their social media documentation habits after a purchase. Kristina (pseudonym), a 23-year-old Norwegian, explains:

"I think if I found something that I really like, that I think it's like a really great thing for me then I would probably not post it saying "Hey I just bought this", but I'd probably do it a bit more discrete, maybe post a photo of me, with it, on Instagram, so you could see it, but it wouldn't be like branding, more like an indirect way [...] But I know I would never buy a t-shirt and take a picture of that $t$-shirt and post it on any social media" (Participant 5, female, Norwegian, 23).

On the contrary, others declare this is an important part of their shopping experience. Marie, for instance, recounts:

"Oh yeah... I would be like "oh, new dress, new goodie for yesterday, changed my life”... You know when I purchase something it's something that I really thought about, usually I don't really buy it straight after I wanted to buy it... I would take a few weeks before buying it, so I have the time to really desire it... when I finally purchased it makes really excited that I finally own it...and I was put it on social media straight away... I feel people might find stylish...to give ideas to people”. (Participant 17, female, 23, French). 
Another element that contributes to this extended shopping experience is that social media spaces come to represent for younger consumers a kind of "customer care" space, whereby shoppers post negative content on a brand or product page after the purchase and aim to engage in direct communication with the producer of a product. Nina (pseudonym), tells us her experience of using social media as "customer care" and explains why she believes this is more effective than more traditional forms of corporate communications with customers:

"I know a few people that have done that... as in for places like Tesco, Superdrug for a product that was already open...something like that. And it seems they answered quite quickly cos they do it on FB, Instagram, they act like a customer service. And I did a few times actually say that I like a brand, and they've got back to me saying "lovely that you loved it", because I was kind of reviewing them [..+. I think that's just an easier way of getting the response you need and get it sorted out quicker. I do think on social media it works better" (Participant 7, female, British, 21).

We argue that these insights bring to the surface how the shopping experience embraces the digital dimension in a multi-dimensional framework where digitally-mediated forms of sociality are pervasive. For our participants, these digital-mediated exchanges are naturally perceived as a legitimate part of the experience around a purchase, and have significant relevance not only when it comes to making a decision to buy, but as a social device for identity and peer acceptance.

\subsection{Social media as aspirational environments}

Another aspect that emerges as important in the extended shopping experiences here outlined is the strong perception of trust that some participants display in the opinion of bloggers and their reviews of products. Alongside the "aspirational" labour that connotes the communication of bloggers (Duffy, 2016) there seems to be an 'aspirational' side also on the side of young consumers who trust 
blogger reviews and these come to influence their purchase decision. Hari, whom we already met, describes this as follows:

"[Do you trust bloggers reviews?] Absolutely! For instance, I bought this make up brush...all of YouTube, social media...the only reason I bought was social media, and YouTube and I'm so thankful I did. There was this lady I used to follow, and the stuff she made was really lovely and I definitely bought things because of her, I trusted her work" (Participant 2, female, British, 23).

Others, however, take a more negative stance on this activity and argue this is an 'easy' playground upon which to achieve social acceptance. It is interesting to note a gender dynamic here at play; the female consumers we have interviewed seem to have a more favourable opinion of this practice, while male consumers seem to interpret this more frequently as part of a broader process of attention seeking and aspirational social recognition that does not necessarily have to do with the search for an opinion or advice in relation to a prospective purchase. See Mick, below, for instance, arguing that:

"I think people like sharing things, they like hear good stuff about them, so I think now especially with social media has made them so easy, you see lots of these snaps, and posts, with boys and girls posting "how do I look like”, or selfies...'cos selfies are big things now... and they always find ways to be on a screen... they always put a quote like "I'm wearing this" so it's kinda like they use like an inspiration quote to say "look what I'm wearing what do you think" to get people to say "oh I like you [...] Most of the times I feel like they do it for likes, I mean... cos I've seen that happening, with my other family members who would put pictures of them while they shop and they just want the like, so they look for the attention, not the opinions... cos I find sometimes they get opinions and they don't go with that opinion anyway... so they would ask the question and at the end of the day they made up their mind" (Participant 11, male, British, 22). 
A conspicuous case of this aspirational shopping experience can be found in Monica (pseudonym), an Italian student in London who is both a heavy shopper and social media user. Monica is somewhat an archetypal case to conclude this account of the networked shopping experience. We meet in central London when she recounts to us her fluid, digital-and-physical, ostensibly experiential notion of consumption:

"I liked it for some time to do shopping online, on websites such as Mother Rocks, Hot Mess, they had these things a bit like 'Princess of Instagram' style... this is the kind of ideology behind these brands. You can be the kind of person who dress in pink for a while, has some spectacular items, something Kawai style... Also Vice Magazine articles influence me in my fashion identity, have you heard for instance about Health Goth? It was a spark, a fashion style that has never existed. That was an article telling about this Facebook group, that I can't recall the name, which had these goth tones and items from street brands such as Nike, or Adidas...and other things from Central St Martins, and emergent designers. This was then appropriated by Topshop and Urban Outfitters and broke through a little, so I also dived into this trend. Now I don't do it anymore, you know, it's become heavy to keep up with the Instagram pace, understand what is trendy and what is not... and I spent thousands of pounds last year for disposable clothes ...” (Participant 4, female, Italian, 22).

These accounts bring us to two initial conclusions. On the one hand, these illustrate how the idea of an "extension" of the self' in consumption throughout the advancement of digitally-mediated forms of communication is a key aspect that requires consideration for retail research, as mobile technologies of communication come to be part of a social setting in which the visit to a real point of sale represents just one aspect in a variously faceted dynamic. Furthermore, these have a notably experiential nature; this complements findings in Weinberger et al. (2017) that consumption cultures among middle class 'emerging adults' are connoted by such experiential dimension. If, for 
them, this represents a component in the imagination of their 'future selves', here it serves a need of socialization and recognition that clearly plays a key role in their shopping preferences. While some retailers have clearly embraced this dimension (e.g., Hollister), others are still nurturing through site-specific innovations (e.g. augmented reality, designated areas for social media sharing) to construct retail environments that favour this 'sharing' experience. These insights show the initial stages of an ongoing process of cultural transformation of retail as a social practice, of which younger consumers seem to be at the forefront, and that needs to be taken into adequate consideration.

\section{Discussion and conclusion}

This study extends the previous ones on the impact of new technology on retailing (Demirkan and Spohrer, 2014; Pantano, 2014; Hristov and Reynolds, 2015; Hagberg et al., 2016; Pantano, 2016; Willems et al., in press.; Bertacchini et al., 2017), by introducing the concept of shopping as "networked experience", as an extension of the traditional in-store shopping activity towards the network.

Drawing upon the notion of the "experience economy" (Pine and Gilmore 1998), scholars and practitioners are actually pushed to reconsider the role of traditional shopping as in-store experience that is evolving fast as an effect of the continuous progress into communication technologies. This concept contributes to knowledge development by linking research in retail with work in the area of consumer culture, as evidence by the three main themes related to the youth perception of shopping experience: (i) the seamless blend between retail access and online shopping, (ii) the instrumental use of social media to the aim of empowering the shopping experience, and (iii) the role of social media as "aspirational devices" and their capacity to influence the purchase decision. Our findings highlight how, among young consumers, an intensive use of social media and digital communication technologies emerges as an integral part of the shopping experience inside and 
outside the store, as digital communication technologies enable the collection of information, the sharing of part of this information with other consumers, and the creation of new digitally-mediated relationships with retailers (in accordance with Arvidsson and Caliandro, 2016; Sheth and Solomon, 2014). Extending the work of Rapp and colleagues (2015), our work shifts from the perspective of consumer-to-employee relationships as affected by the technology towards the consumer-toconsumer relationships as moving digital, by underling the specific effects on the new sense of sociality experienced in-store. This is very much an "experiential" notion insofar as it fosters a new kind of experience of access to the store, whereby the store itself embraces the practices of digitally-mediated communication for the enhancement of purchases. This study further contributes to the emerging discussion on the importance of including the social aspects in the online and offline retail settings (Papagiannidis et al., 2017; Pantano and Gandini, 2017), by providing evidence on the impact of online social interaction in the offline shopping experience. Similarly, our findings extend the previous literature on social commerce as a new form of shopping led by social interactions (Ahmad et al., 2017; Hajli and Sims, 2015; Liang et al., 2011; Lin and Wang, 2017; Wang and $\mathrm{Yu}, 2017)$. These results in what we call a "networked shopping experience", that extend the traditional physical boundaries of the store throughout the advancement of digitally-mediated forms of communication (Sheth and Solomon, 2014) and combines new forms of "network sociality" (Wittel, 2001) to create a new sense of shopping beyond its place meaning.

From a practical perspective, marketers and retailers should consider that the shopping experience is no longer limited to the physical point of sale, and on the consequences of this evolution. Digitallymediated forms of communication intervene to play a key role in the way in which consumers access information, share information and interact with retailers. As a consequence, retailers should be able to provide a shopping experience that is natively networked, and that makes the best use of tools such as Facebook, Twitter, WhatsApp to reinforce consumer loyalty, enhance the service and generate positive eWOM. Thus, they are also required to put more effort into exploiting these technologies simultaneously to engage more consumers. 
Although this study offers significant insights on the evolution of the shopping experience in the diffusion of digitally-mediated communication, there are also few limitations that should be taken into account. The first one is related to the sample. The number of 20 interviewees is acceptable for an exploratory study, but would encourage more quantitative and larger studies to achieve more generalisable results. It must also be acknowledged that the present findings and reflections are focused on a specific cohort of young, highly-digitised consumers. Future studies might seek to replicate this study by engaging in a comparative framework that investigates the differences in behaviours on the basis of age and technological savviness. Similarly, future studies might also replicate the research in different geographic areas and make cross-countries comparisons to better understand whether the evolution in the consumer experience here identified is a result of the diffusion and usage of digitally-mediated tools for social interaction, or other factors that may intervene within this context should be further explored.

\section{References}

Ahmad, S.N. and Laroche, M. (2017), “Analyzing electronic word of mouth: a social commerce construct”, International Journal of Information Management, Vol. 37 No. 3, pp. 202-213

Ahuvia, A. C. (2005), "Beyond the extended self: Loved objects and consumers' identity narratives", Journal of Consumer Research, Vol. 32 No. 1, pp. 171-184.

Akaka, M.A., Vargo, S.L. and Schau, H.J. (2015), “The context of experience”, Journal of Service Management, Vol. 26 No. 2, pp. $206-223$.

Arvidsson, A. and Caliandro, A. (2015), "Brand public", Journal of Consumer Research, Vol. 42 No. 5, pp. 727-748.

Arvidsson, A. (2013), “The potential of consumer publics”, Ephemera, Vol. 13 No. 2, pp. 367. Arvidsson, A. (2009), “The ethical economy: Towards a post-capitalist theory of value”, Capital and Class, Vol. 33 No. 1, pp. 13-29. 
Arvidsson, A. (2005), "Brands: A critical perspective”, Journal of Consumer Culture, Vol. 5 No. 2 , pp. 235-258.

Atwal, G. and Williams, A. (2009), "Luxury brand marketing-the experience is everything!", The Journal of Brand Management, Vol. 16 No. 5, pp. 338-346.

Backstrom, K. and Johansson, U. (2006), "Creating and consuming experiences in retail store environments: comparing retailer and consumer perspectives", Journal of Retailing and Consumer Services, Vol. 13, pp. 417-430.

Baker, J., Parasuraman, A., Grewal, D. and Voss, G.B. (2002), "The influence of multiple store environment cues on perceived merchandise value and patronage intentions", Journal of Marketing, Vol. 66, pp. 120-141.

Belk, R. W. (2013), "Extended self in a digital world”, Journal of Consumer Research, Vol. 40 No. 3, pp. 477-500.

Belk, R. W. (1989), "Extended self and extending paradigmatic perspective”, Journal of Consumer Research, Vol. 16 No. 1, pp. 129-132.

Bertacchini, F., Bilotta, E. and Pantano, P. (2017), "Shopping with a robotic companion", Computers in Human Behavior, Vol. 77, pp. 382-395.

Bryman, A. (2015), Social Research Methods, $5^{\text {th }}$ Edition, Oxford University Press.

Buke R.R. (2002), "Technology and the customer interface: what consumers want in the physical and virtual store", Journal of the Academy of Marketing Science, Vol. 30 No. 4, pp. 411-432.

Campo, K. and Breugelmans, E. (2015), "Buying groceries in brick and click stores: category allocation decisions and moderating effect of online buying experience", Journal of Interactive Marketing, Vol. 31, pp. 63-78.

Caru, A. and Cova, B. (2003), "Revisiting consumption experience: a more humble but complete view of the concept", Marketing Theory, Vol. 3 No.2, pp. 267-286.

Chen, J. and Shen, X.-L. (2015), “Consumers' decisions in social commerce context: an empirical investigation", Decision Support Systems, Vol. 79, pp. 55-64. 
Chen, Y., Wang, Q.I. and Xie, J. (2011), “Online social interactions: a natural experiment on word of mouth versus observational learning", Journal of Marketing Research, Vol. 48 No. 2, pp. 238254.

Demirkan, H. and Spohrer, J., (2014), "Developing a framework to improve virtual shopping in digital malls with intelligent self-service systems", Journal of Retailing and Consumer Services, Vol. 21 No. 5, pp. 860-868.

Donovan, R.J., Rossiter, J.R., Marcoolyn, G. and Nesdale, A. (1994), "Store atmosphere and purchasing behavior", Journal of Retailing, Vol. 70 No. 3, pp. 283-294.

Duffy, B. E. (2016). The romance of work: Gender and aspirational labour in the digital culture industries. International Journal of Cultural Studies, 19(4), 441-457.

Ferber, R. (1977). Research by convenience. Journal of Consumer Research, 4 (1), 57-58.

Gallouj, F., Weber, K.M., Stare, M. and Rubalcaba, L. (2015), “The futures of the service economy in Europe: a foresight analysis", Technological Forecasting and Social Change, Vol. 94, pp. 80-96. Hagberg, J., Sundstrom, M. and Egels-Zandén, N. (2016), “The digitalization of retailing: an exploratory framework", International Journal of Retail and Distribution Management, Vol. 44 No. 7, pp. 694-712.

Hajli, N. and Sims, J. (2015), "Social commerce: the transfer of power from sellers to buyers", Technological Forecasting and Social Change, Vol. 94, pp. 350-358.

Hew, J.-J., Lee, V.-H., Ooi, K.-B. and Lin, B. (2016), "Mobile social commerce: the booster for brand loyalty?", Computers in Human Behavior, Vol. 59, pp. 142-154.

Hristov, L. and Reynolds, J. (2015), "Perceptions and practices of innovation in retailing", International Journal of Retail and Distribution Management, Vol. 43 No. 2, pp. 126-147.

Huang, Z. and Benyoucef, M. (2013), "From e-commerce to social commerce: a close look at design features", Electronic Commerce Research and Applications, Vol. 12, pp. 246-259. 
Jones, P., Comfort, D., Clarke-Hill, C. and Hillier, D. (2010), "Retail experience stores: experiencing the brand at first hand", Marketing Intelligence and Planning, Vol. 28 No. 3, pp. 241248.

Kim, H., Suh, K.-S. and Lee, U.K. (2013), "Effect of collaborative online shopping on shopping experience through social and relational perspectives", Information and Management, Vol. 50 No. 4, pp. 169-180.

Kindstrom, D., Kowalkowski, C. and Sandberg, E. (2013), "Enabling service innovation: A dynamic capabilities approach”, Journal of Business Research, Vol. 66, pp. 1063-1073.

Klein, J.F., Faalk, T., Esch, F.-R. and Gloukhovstev, A. (2016), "Linking pop-up brand stores to brand experience and word of mouth: the case of luxury retail”, Journal of Business Research, Vol. 69, pp. 5761-5767.

Lee, M. K.O., Shi, N., Cheung, C.M.K., Lim, K.H. and Sia, C.L. (2011), “Consumer's decision to shop online: the moderating role of positive informational social influence", Information and Management, Vol. 48 No. 6, pp. 185-191.

Letaifa, S.B., Edvardsson, B. and Tronvoll, B. (2016), "The role of social platforms in transforming service ecosystems", Journal of Business Research, Vol. 69, pp. 1933-1938.

Liang, T.-P., Ho, Y.-T., Li, Y.-W. and Turban, E. (2011), "What drives social commerce: the role of social support and relationship quality", International Journal of Electronic Commerce, Vol. 16 No. 2, pp. 69-90.

Lin, X., Li, Y. and Wang, X. (2017), "Social commerce research: definition, research themes and the trends", International Journal of Information Management, Vol. 37 No. 3, pp. 190-201.

Lu, B., Fan, W. and Zhou, M. (2016), "Social presence, trust and social commerce purchase intention: an empirical research”, Computers in Human behavior, Vol. 56, pp. 225-237.

Lury, C. (2004). Brands: The logos of the global economy. London: Routledge.

Lush, R.F., Vargo, S.L. and O’Brien, M. (2007), “Competing through service: insights from service-dominant logic", Journal of Retailing, Vol. 83, pp. 5-18. 
Lusch, R.F. and Spohrer, J.C. (2012), “Evolving service for a complex, resilient, and sustainable world”, Journal of Marketing Management, Vol. 28 No. 13-14, pp. 1491-1503.

Marwick, A. E. (2015), "Instafame: Luxury selfies in the attention economy", Public Culture, Vol. 27 No. 175, pp. 137-160.

Mishra, A., Maheswarappa, S.S., Maity, M. and Samu, S. (in press), “Adolescent's eWOM intentions: an investigation into the roles of peers, the Internet and gender", Journal of Business Research.

Mohan, G., Sivakumaran, B. and Sharma, P. (2012), “Store environment's impact on variety seeking behaviour", Journal of Retailing and Consumer Services, Vol. 19, pp. 419-428.

Nsairi, Z.B. (2012), "Managing browsing experience in retail stores through perceived value: implications for retailers", International Journal of Retail and Distribution Management, Vol. 40 No. 9, pp. $676-698$.

Öberseder, M., Schlegelmilch, B. B., \& Gruber, V. (2011). "Why don't consumers care about CSR?": A qualitative study exploring the role of CSR in consumption decisions. Journal of Business Ethics, 104(4), 449-460.

Pantano, E. (2016), "Benefits and risks associated with time choice of innovating in retail settings", International Journal of Retail and Distribution Management, Vol. 44 No. 1, pp. 58-70.

Pantano, E., Priporas, C.V. and Dennis, C. (in press.), "Retailer innovation push behaviour in the new service economy: A smart retailing model”, International Journal of Retail and Distribution Management.

Pantano, E. and Gandini, A. (2017), "Exploring the forms of sociality mediated by innovative technologies in retail settings", Computers in Human Behavior, Vol. 77, pp. 367-373.

Pantano, E. and Migliarese, P. (2014), "Exploiting consumer-employee interactions in technologyenriched retail environments through a relational lens", Journal of Retailing and Consumer Services, Vol. 21 No. 6, pp. 958-965. 
Papagiannidis, S., Bourlakis, M., Alamanos, E. and Dennis, C. (2017), "Preferences of smart shopping channels and their impact on perceived wellbeing and social inclusion", Computers in Human Behavior, Vol. 77, pp. 396-405.

Rapp, A., Agnihotri, R., Baker, T.L. and Andzulis, J.M. (2015), “Competitive intelligence collection and use by sales and service representatives: how managers' recognition and autonomy moderate individual performance", Journal of Academy of Marketing Science, Vol. 43 No. 3, pp. 357-374.

Reinstaller, A. and Sanditov, B. (2005), "Social structure and consumption: on the diffusion of consumer good innovation”, Journal of Evolutionary Economics, Vol. 14, pp. 505-531.

Robinson, O. C. (2014). Sampling in interview-based qualitative research: A theoretical and practical guide. Qualitative Research in Psychology, 11(1), 25-41.

Vargo, S.L. and Lusch, R.F. (2004), "Evolving to a new dominant logic for marketing”, Journal of Marketing, Vol. 68, pp. 1-17.

Vargo, S.L. and Lusch, R.F. (2008), "Service-dominant logic: continuing the evolution”, Journal of the Academy of Marketing Science, Vol. 36 No. 1, pp. 1-10.

Verhoef, P.C., Lemon, K.N., Parasuraman, A., Roggeveen, A., Tsiros, M. and Schlesinger, L.A. (2009), "Customer experience creation: determinants, dynamics and management strategies", Journal of Retailing, Vol. 85 No. 1, pp. 31-41.

Wang, Y. and Yu, C. (2017), "Social interaction-based consumer decision-making model in social commerce: the role of word of mouth and observational learning", International Journal of Information Management, Vol. 37 No. 3, pp. 179-189.

Weinberger, M. F., Zavisca, J. R., \& Silva, J. M. (2017). Consuming for an imagined future: Middle-class consumer lifestyle and exploratory experiences in the transition to adulthood. Journal of Consumer Research, 44(2), 332-360. 
Willems, K., Smolders, A., Bregman, M., Luyten, K. and Schoning, J. (2017), "The path-topurchase is paved with digital opportunities: an inventory of shopper oriented retail technologies", Technological Forecasting and Social Change, Vol. 124, pp. 228-242.

Wittel, A. (2001), “Toward a network sociality”, Theory, Culture and Society, Vol. 18 Vol. 6, pp. $51-76$

Yadav, M.S., de Valck, K., Henning-Thurau, T., Hoffman, D.L. and Spann, M. (2013), "Social commerce: a contingency framework for assessing marketing potential", Journal of Interactive Marketing, Vol. 27, pp. 311-323.

Yoon, S.-J. (2013), “Antecedents and consequences of in-store experiences based on an experiential typology”, European Journal of Marketing, Vol. 47 No. 5/6, pp. 693-714.

Zhang, J. (2010), "The sound of silence: observational learning in the US kidney market", Marketing Science, Vol. 29 No. 2, pp. 315-335.

Zhang, K.Z.K. and Benyoucef, M. (2016), "Consumer behavior in social commerce: a literature review", Decision Support Systems, Vol. 86, pp. 95-108.

Zhang, H., Lu, Y., Gupta, S. and Zhao, L. (2014), "What motivates customers to participate in social commerce? The impact of technological environments and virtual customer experience", Information and Management, Vol. 51, pp. 1017-1030.

Zukin, S. and Maguire, J. S. (2004), "Consumers and consumption”, Annual Review of Sociology, Vol. 30, pp. 17. 